\title{
O PAPEL DA GESTÃO COLABORATIVA NOS FESTIVAIS CRIATIVOS: O CASO DA PRODUÇÃO DO CARNAVAL EM VITORIA-ES
}

\author{
The role of collaborative management in creative festivals: the case of carnival production in Vitória-ES \\ El papel de la gestión colaborativa en los festivales creativos: el caso de la producción del carnaval en Vitória-ES
}

Alexandre Reis Rosa

Universidade Federal do Espirito Santo (UFES), Vitória,

DOI: https://doi.org//10.18472/cvt.20n1.2020.1661

Redalyc: http://www.redalyc.org/articulo.oa?

ES, Brasil

id $=115462634011$

alexandre.r.rosa@ufes.br

Ilane Coutinho Duarte Lima

Universidade Federal do Espirito Santo (UFES), Vitória,

ES, Brasil

ilanecoutinho3@gmail.com

Mirelle Simões de Aguiar

Universidade Federal do Espirito Santo (UFES), Vitória,

ES, Brasil

mirellesimoes@gmail.com

Recepción: 14 Septiembre 2018

Aprobación: 13 Mayo 2020

\section{RESUMo:}

O Carnaval, apesar de ser um tipo de festival de celebração cultural, tem sido visto como uma importante atividade econômica e turística que movimenta uma extensa cadeia produtiva. Embora os festivais ocorram em quase todo o mundo, e o Carnaval em particular nas diversas regiões brasileiras, eles são pouco estudados do ponto de vista da sua organização e gestão. Usando como exemplo o Carnaval de Vitória-ES, o objetivo deste artigo consiste em analisar e compreender como ocorre o processo de colaboração interorganizacional inerente à produção do desfile das escolas de samba. Para isso realizamos um estudo qualitativo com aplicação do método de estudo de caso, entrevistas em profundidade e análise documental. Os resultados mostram que a compreensão do processo colaborativo é importante para o próprio desenvolvimento do festival, tendo em vista que as pesquisas na área de gestão de eventos e de festivais mostram que parte significativa do sucesso e fracasso neste campo depende sobretudo de uma gestão adequada dos stakeholders. Ou seja, da dinâmica de relacionamento entre os múltiplos atores que fazem o espetáculo acontecer.

Palavras-chave: Evento Artístico Cultural, Gestão Colaborativa, Carnaval, Vila Velha-ES.

\section{Abstract:}

Carnival as a kind of festival of cultural celebration has been seen as an important economic and tourist activity that moves an extensive productive chain. Although festivals of cultural celebration take place everywhere in the world and Carnival in particular in the different Brazilian regions, they are little studied from the point of view of their organization and management. Using the Carnival of Vitória-ES as an example, the objective of this article is to analyze and understand how the interorganizational collaboration process inherent in the production of the samba schools parade occurs. For this, we carried out a qualitative study using the case study method, in-depth interviews and document analysis. The results show that the understanding of the collaborative process is important for the development of the festival, considering that research in the area of event and festival management shows that a significant part of the success and failure in this field depends mainly on an adequate management of the stakeholders. In other words, the dynamics of the relationship between the multiple actors that make the show happen.

KEYwords: Arts and Culture Events, Collaborative Management, Carnival, Vila Velha-ES.

\section{RESUMEN:}

El carnaval, a pesar de ser un tipo de festival de celebración cultural, ha sido visto como una importante actividad económica y turística que mueve una extensa cadena de producción. Aunque los festivales tienen lugar en casi todo el mundo, y el Carnaval en particular en diferentes regiones brasileñas, están poco estudiados desde el punto de vista de su organización y gestión. Utilizando 
el Carnaval de Vitória-ES como ejemplo, el objetivo de este artículo es analizar y comprender cómo se produce el proceso de colaboración interorganizacional inherente a la producción del desfile de la escuela de samba. Para esto, realizamos un estudio cualitativo utilizando el método de estudio de caso, entrevistas en profundidad y análisis de documentos. Los resultados muestran que comprender el proceso de colaboración es importante para el desarrollo del festival, teniendo en cuenta que la investigación en el área de la gestión de eventos y festivales muestra que una parte significativa del éxito y el fracaso en este campo depende sobre todo de una gestión adecuada de los eventos. partes interesadas En otras palabras, la dinámica de la relación entre los múltiples actores que hacen que el espectáculo suceda.

Palabras Clave: Evento Artístico Cultural, Gestión colaborativa, Carnaval, Vila Velha-ES.

\section{INTRODUÇÃo}

A economia criativa surge no cenário econômico pós-industrial como um paradigma emergente que congrega um conjunto de atividades produtivas, cujo funcionamento envolve o ato criativo e a geração simultânea de valor econômico e simbólico (Throsby, 1995). No núcleo da economia criativa estão as indústrias criativas, que se alimentam da criatividade para desenvolver produtos e serviços que abrangem as diversas expressões culturais no campo das artes, do teatro, da música, do cinema, da publicidade, do design, dentre outras (Jeffcutt, 2000).

Entre os setores culturais, a Secretaria da Economia Criativa, vinculada ao antigo Ministério da Cultura (SEC-MinC) estabelece três grupos denominados de setores criativos nucleares - patrimônio natural e cultural, espetáculos e celebrações, artes visuais e artesanato, livros e periódicos, design e serviços criativos, audiovisual e mídias interativas - setores criativos relacionados - turismo, esportes e lazer - e patrimônio imaterial - expressões e tradições orais, rituais, línguas e práticas sociais. No âmbito dos setores criativos nucleares, os espetáculos e celebrações compreendem uma parte importante das manifestações culturais brasileiras, entre as quais o carnaval, que recentemente tem sido considerado uma festa popular com enorme potencial criativo e econômico (Prestes Filho, 2009).

Considerando o contexto apresentado, da economia criativa como sendo uma alternativa de desenvolvimento que articula diversas indústrias criativas, entre as quais, a indústria dos festivais - como é o caso do Carnaval, cuja produção depende da coordenação do setor público e da colaboração dos demais stakeholders para obter sucesso - nosso objetivo é analisar e compreender como ocorre o processo de colaboração interorganizacional na produção do desfile das escolas de samba do Carnaval na cidade de Vitória. Ao cumprir este objetivo, esperamos suprir algumas lacunas importantes nas pesquisas sobre gestão colaborativa de eventos e festivais, sobre gestão e organização do carnaval e sobre as indústrias que compõem a economia criativa. Cada vez mais estes temas têm chamado atenção dos pesquisadores em virtude de terem sido negligenciados diante de outros temas mais tradicionais no campo dos estudos sobre gestão e organização.

A gestão colaborativa tem sido explorada principalmente no campo da gestão pública como importante ferramenta de análise da governança pública e dos formatos híbridos de gestão que vêm caracterizando a atuação recente dos governos diante das inúmeras oportunidades advindas de parcerias com empresas e ONGs (Emery \& Giauque, 2014). Políticas públicas, obras de infraestrutura, e projetos de desenvolvimento econômico e social são algumas das possibilidades que a gestão colaborativa pode trazer para o futuro da gestão pública (Farazmand, 2012). Neste sentido, ao analisar a produção do Carnaval em Vitória, tendo o governo local como um dos atores envolvidos na gestão e organização do evento, a pesquisa traz subsídios importantes para compreender a gestão colaborativa em âmbito local.

Sobre a gestão de eventos e de festivais, os estudos mostram que existem poucas pesquisas realizadas fora do eixo EUA-Europa (Getz, 2010). Esta lacuna tem sido apontada como um problema diante da recente exposição que os países periféricos têm tido aos eventos globais, tais como, por exemplo, os grandes festivais de música, as competições esportivas e congressos profissionais. Sabe-se muito pouco sobre como estes 
eventos são administrados nestes países e sobre como eles enfrentam as dificuldades inerentes a este tipo de empreendimento (Getz \& Andersson, 2010).

No caso específico do Carnaval, desde o final dos anos 1970 as agremiações carnavalescas e o seu processo de produção de desfiles têm sido objeto de interesse de inúmeras pesquisas no campo da sociologia e da antropologia. O interesse pelo Carnaval como objeto de estudo advém do seu significativo impacto social e cultural. Além disso, a profissionalização do setor tem revelado também como uma atividade com significativo impacto econômico (Prestes Filho, 2009) e turístico (Getz \& Page, 2016). Apesar disso, ainda existem poucos estudos sobre a gestão e a organização do Carnaval no Brasil (e.g. Tureta \& Arau\#jo, 2013) e destes poucos, apenas os estudos de Cabral, Krane e Dantas (2013) e Cabral e Krane (2018) abordaram a gestão colaborativa na produção de festivais como o Carnaval.

\section{Carnaval Como Festival CRiativo E COMO PRoJeto tURÍstico}

Segundo DaMatta (1979), o carnaval no Brasil representa uma das dimensões simbólico-culturais que melhor expressam a dinâmica da sociedade brasileira. Apesar disso, autores como Risério (1995) chamam atenção para a pluralidade de manifestações culturais que estão sob o termo "Carnaval", revelando com isso um panorama da festa carnavalesca que é formado por vários carnavais. Assim, podemos falar do Carnaval carioca, do Carnaval do Recife e Olinda ou do Carnaval de Salvador, consideradas como algumas das mais vigorosas e conhecidas festas do gênero no Brasil. O Carnaval carioca, por exemplo, caracteriza-se, especialmente, por sua condição de espetáculo. O Carnaval de Pernambuco tem sua marca mais associada à tradição e participação popular. Já o Carnaval soteropolitano, caracterizado pelos famosos trios elétricos, também tem grande apelo popular, porém é muito mais afeito a hibridações e inovações do que o frevo pernambucano.

$\mathrm{Na}$ literatura sobre gestão de eventos (Getz, 2010), o carnaval é visto como um tipo de festival de celebração cultural, cuja organização envolve diversos atores, tanto do setor público, como do setor privado. Além disso, a sociedade civil também se envolve de forma intensa por meio de organizações sociais que atuam na área cultural. Esta gama de atores, de diferentes setores, caracterizam os festivais como "indústrias mistas" (Andersson \& Getz, 2009), ou seja, indústrias cuja gestão e organização são marcadas pela presença de diversos stakeholders (Alonso \& Bressan, 2013).

Parte significativa do sucesso ou do fracasso de um festival depende de uma boa gestão dos stakeholders (Getz, 2002). No caso do Carnaval, e em contextos de cidades como Rio de Janeiro, Salvador e Recife entre outros, um dos stakeholders mais importantes é o setor púbico (Getz \& Andersson, 2010), em todoas as esferas governamentais. Por tanto, exigem que as prefeituras assumam a coordenação do evento (Santos, 2010), articulando secretarias de governo (geralmente de Cultura e Turismo), segurança pública e trânsito (Polícia Militar e Guarda Municipal), Ligas de escolas de samba, mídia escrita e televisiva, empresas privadas que patrocinam as festas, e toda sorte de atores envolvidos com a festa.

Durante um festival com proporções globais, como é o caso do Carnaval carioca, a cidade passa a funcionar como uma espécie de campo criativo aberto, completamente exposta ao contato com milhares de turistas de diversos países (Scott, 2008), tendo sua geografia alterada pela dinâmica da festa e pela estrutura que se desenvolve em torno da sua produção (Blass, 2008). Segundo Getz e Page (2016), os festivais atuam como importantes motivadores para o turismo, pois numerosos turistas são atraídos por vários tipos de eventos como este em uma grande variedade de destinos ao redor do mundo, fazendo com que o desenvolvimento do turismo em um determinado destino esteja diretamente relacionado ao bom gerenciamento do festival. Assim, a colaboração entre os diversos atores envolvidos é considerada como fundamental para o funcionamento do festival, pois como se trata de uma indústria mista, cujo financiamento envolve recursos públicos e privados, trata-se de um dos pontos mais importantes do planejamento municipal (Comunian, 2011). 

PROD...

\section{OrganizaÇÃo do carnaval e a gestão colaborativa}

No nível interorganizacional, a colaboração refere-se a um tipo de relação entre os atores envolvidos que possibilita a construção de parcerias intersetoriais (governo, mercado e sociedade civil) capazes de gerar valor público (Sandfort \& Milward, 2008). Um dos modelos de análise mais aceitos na literatura sobre colaboração interorganizacional é o proposto por Ansell e Gash (2008), conforme apresentado na Figura 1. Sua principal vantagem está na abrangência das variáveis, que vão desde os antecedentes do processo colaborativo, até os resultados obtidos com a colaboração. Deste modo, torna-se possível compreender o processo colaborativo de forma sistêmica, levando-se em conta não apenas o processo em si, mas sobretudo os elementos que o antecedem e suas consequências em termos de resultados.

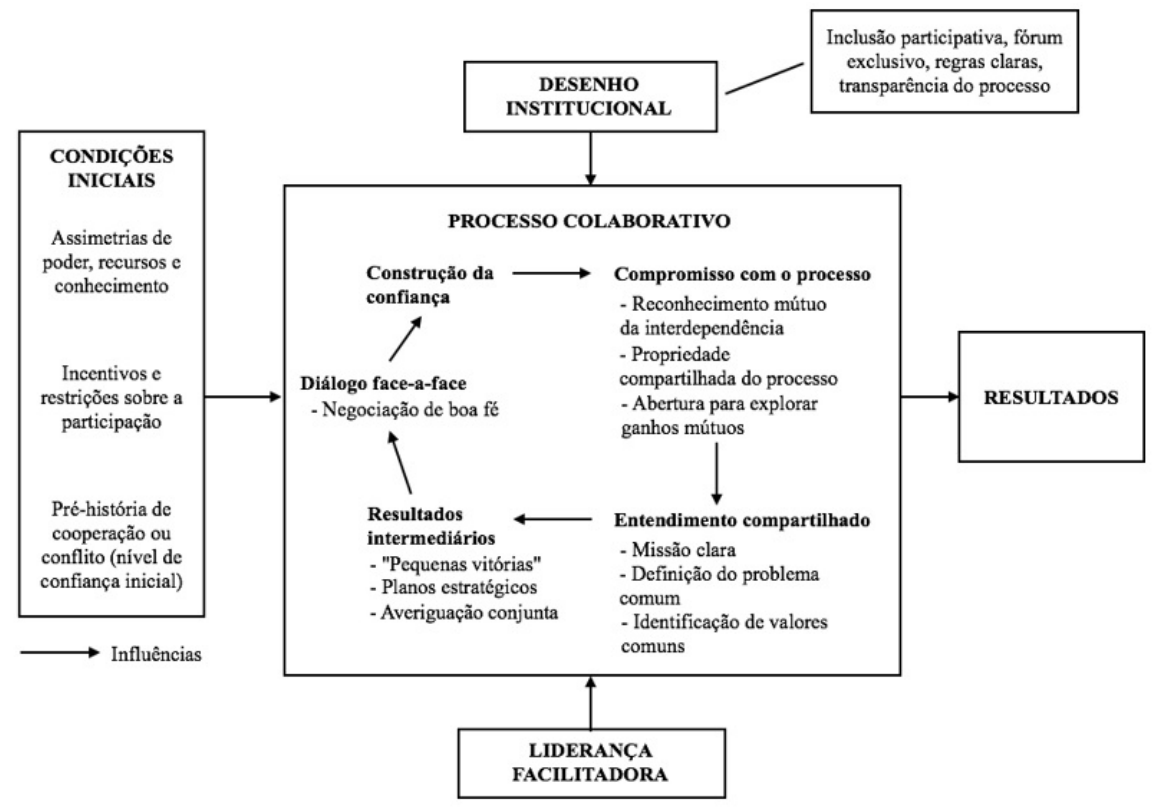

Figura 1. Modelo de gestão colaborativa

Fonte: Adaptado de Ansell e Gash (2008, p. 550).

Outro aspecto importante do modelo é o caráter circular que o processo de colaboração assume. $\mathrm{O}$ ciclo tem início nos diálogos entre os stakeholders e, a partir disso, desencadeia os demais processos que acabam realimentando os diálogos e promovendo novas interações durante a organização de um dado evento. Dependendo do desenho institucional e da liderança facilitadora, o processo pode influenciar na relação os diversos stakeholders (Ansell \& Gash, 2008).

Embora amplamente aceita na literatura sobre gestão colaborativa, poucos estudos testaram este modelo na gestão de festivais, principalmente festivais em países fora do eixo EUA-Europa (Getz, 2010). No Brasil, conforme já mencionado, os únicos estudos encontrados foram feitos por Cabral, Krane e Dantas (2013) e Cabral e Krane (2018), que analisaram a gestão colaborativa na produção do carnaval em Salvador.

\subsection{Condições iniciais}

A primeira das quatro variáveis críticas, apresentada no modelo de Ansell e Gash (2008), define que as condições presentes no início da colaboração podem facilitar ou desencorajar a atuação das partes envolvidas no processo, uma vez que a origem dos interessados e, consequentemente, seus históricos de conquistas e dificuldades acabam influenciando na formação e manutenção da rede colaborativa. Deste modo, três variáveis são decisivas para o estabelecimento de uma gestão colaborativa eficaz: assimetria entre os recursos 
ou o poder das diferentes partes interessadas; os incentivos que estas possuem para colaborarem; e os antecedentes de conflito ou cooperação entre estas (Ansell \& Gash, 2008).

\subsection{Desenho institucional}

A segunda variável crítica proposta por Ansell e Gash (2008) refere-se aos protocolos e regras básicas necessárias à colaboração e cruciais para a legitimidade processual desta gestão. Fung e Wright (2003) atribuem ao desenho institucional o êxito ou fracasso dos processos participativos. Usualmente, a literatura afirma que esta estrutura deve ser aberta e inclusiva, para que os grupos envolvidos se sintam parte da estrutura processual e desenvolvam compromisso com o processo (Ansell \& Gash, 2008). Deste modo, observa-se que os modelos participativos de gestão tendem a apresentar uma estrutura de decisóes bottom-up (de baixo para cima) em oposição ao modelo top-down (de cima para baixo) usualmente aplicado na administração em geral (Fung \& Wright, 2003).

\subsection{Liderança facilitadora}

No processo colaborativo a presença de um líder apresenta algumas peculiaridades, pois a colaboração exige engajamento, debate, inclusão, poder compartilhado e aprendizagem mútua (Chrislip, 2002). Neste cenário, a presença de uma liderança facilitadora é indispensável como forma de gerir as reunióes, permitindo que grupos trabalhem em conjunto e de maneira construtiva. Por se tratar de um modelo de gestão que engloba atores de diferentes setores econômicos, a compreensão do perfil da liderança se mostra de substancial importância para o avanço dos estudos sobre o tema (Chrislip, 2002).

\subsection{Processo colaborativo}

O núcleo central do modelo refere-se ao que Ansell e Gash (2008) descrevem um processo cíclico, uma vez que depende de um clico interativo que envolve comunicação, confiança, compromisso e entendimento em busca dos mesmos resultados. Neste sentido, o diálogo face-a-face é baseado em uma comunicação direta entre todos os envolvidos na colaboração, permitindo a construção de um consenso orientado para ganhos mútuos. Além disso, convém salientar que este tipo de comunicação elimina ruídos que usualmente comprometem o processo de transmissão de uma mensagem. A confiança também é a base para o processo colaborativo, pois a colaboração não é estruturada apenas na negociação, mas na construção da confiança entre todos os envolvidos na rede de colaboração. Já o compromisso com o processo colaborativo é uma variável determinante para o sucesso ou fracasso deste modelo, e está intimamente relacionado à motivação original que cada indivíduo possui para participar da rede de colaboração. É este compromisso que irá sustentar a busca por um entendimento em prol do resultado da experiência colaborativa (Ansell \& Gash, 2008).

\section{Metodologia}

O presente estudo se desenvolveu com base na pesquisa qualitativa do tipo exploratória e descritiva, utilizando-se como estratégia o estudo de caso. Entre os possíveis usos do estudo de caso, foi adotado o estudo de caso qualitativo. A pesquisa qualitativa e\# pautada na análise sobre a dinâmica de interação das pessoas em seus contextos de atuação, trata-se de uma estratégia de pesquisa que aproxima o pesquisador do seu objeto 

PROD...

de estudo, possibilitando tornar o mundo visível a partir de representações produzidas a partir de notas de campo, entrevistas em profundidade, análise de documentos, etc. (Denzin \& Lincoln, 2000).

Entre os documentos utilizados nesta pesquisa estão as normas e resoluções municipais que regulam o carnaval de Vitória, dados e relatórios estatísticos sobre a indústria do carnaval e matérias de jornal sobre as mudanças e os eventos do carnaval em Vitória. Estes documentos ajudaram a compreender o funcionamento da festa e a dinâmica assumida nos últimos anos.

A segunda fonte de coleta de dados foi por meio de entrevistas em profundidade. O número de entrevistas foi definido de acordo com o andamento da pesquisa e do mapeamento de potenciais informantes durante a pesquisa de campo (Noy, 2008). Ao todo foram realizadas 19 (dezenove) entrevistas distribuídas em organizações governamentais, não-governamentais, empresas e sociedade civil, conforme apresentado o Quadro 1, a seguir:

Quadro 1. Organizações de origem dos sujeitos da pesquisa

\begin{tabular}{|l|l|}
\hline SEGMENTO & ORGANIZAÇÃO \\
\hline Governo & $\begin{array}{l}\text { Secretaria Estadual de Turismo (SETUR); Prefeitura } \\
\text { Municipal de Vitória (PMV) / Secretaria de Turismo; } \\
\text { Prefeitura Municipal de Vitória (PMV) / Secretaria de } \\
\text { Cultura }\end{array}$ \\
\hline Empresa & ECOS Eventos \\
\hline Sociedade Civil & $\begin{array}{l}\text { LIESGE (Grupo ESpecial); LIESES (Grupo A); BOA VISTA; } \\
\text { MUG; PIEDADE; JUCUTUQUARA; CHEGOU O QUE } \\
\text { FALTAVA; INDEPENDENTES DE SÃO TORQUATO; } \\
\text { ROSAS DE OURO }\end{array}$ \\
\hline
\end{tabular}

Fonte: Elaborado pelos autores.

Entre as inúmeras técnicas de análise de dados, privilegiamos aqui a análise de conteúdo devido a flexibilidade que essa técnica proporciona, pois por meio dela pode-se analisar qualquer tipo de comunicação que veicule um conjunto de significações, podendo ser do tipo linguístico (na forma escrita ou oral), icônico (sinais, grafismos, imagens, fotos, etc.) ou códigos semióticos (música, objetos, comportamentos, espaço, tempo, etc.). Sua dinâmica pode ser resumida, segundo Bardin (2004, p. 37), como "[...] um conjunto de técnicas de análises das comunicações visando obter, por procedimentos sistemáticos e objectivos de descrição do conteúdo [...] que permitam a inferência”.

\section{A DinÂMica do Festival: Descrevendo o CARNAVAl de Vitória}

Desde o ano de 2001 o carnaval do Espírito Santo esteve sob a organização da Liga Capixaba de Escolas de Samba (LICES), que em 2007 passou a se chamar Liga Espírito-santense das Escolas de Samba (LIESES). No ano de 2017 uma nova organização foi criada, a Liga Independente das Escolas de Samba do Grupo Especial (LIESGE). Desde então as quatorze escolas integrantes do carnaval de Vitória se dividiram nas duas Ligas. Enquanto os desfiles das escolas do Grupo de Acesso ficaram a cargo da LIESES, os do Grupo Especial ficaram por conta LIESGE.

Fazem parte da LIESGE as escolas: Boa Vista, Mocidade Unida da Glória (MUG), Unidos da Piedade, Novo Império, Unidos de Jucutuquara, Andaraí e Pega no Samba e apesar de ter caído esse ano para o acesso, a Pega no Samba foi convidada a integrar a nova liga. As escolas do grupo de acesso continuaram sendo regidas pela LIESES. São elas: Barreiros, Imperatriz do Forte, São Torquato, Tradição Serrana, Chega Mais, Chegou o que Faltava e Rosas de Ouro. Além disso, tem a Federação Capixaba das Escolas de Samba (FECAPES), fundada este ano, com o objetivo de fazer com que as agremiações históricas do carnaval capixaba voltassem 
a desfilar no Sambão do Povo. São as escolas Independente de Eucalipto, Mocidade Serrana, Mocidade da Praia, União Jovem de Itacibá e Império de Fátima.

Uma divisão entre as Ligas é facilmente identificada nas articulações dos presidentes das Escolas de Samba com outros atores envolvidos no processo. No novo modelo de duas ligas, a LIESGE é a única responsável pelo desfile do Grupo Especial, detentora do desfile do sábado. Segundo a instituição, isso torna mais fácil a captação de recursos para sete agremiações em vez de quatorze, como era antes, demonstrando que o "produto final" apresentado pelas escolas é mais grandioso e qualificado. As escolas pertencentes à LIESES, formada somente pelas agremiações do Grupo de Acesso, sentem-se prejudicadas financeiramente, já que, para a iniciativa privada, os desfiles de sábado aparentam ser mais interessantes para investimentos, muito em razão das agremiações envolvidas.

O regulamento para o rebaixamento e ascensão das agremiações continua o mesmo. A escola do Grupo Especial que ficar classificada em $7^{\text {a }}$ lugar será rebaixada para o Grupo de Acesso e desfilará na sexta-feira no próximo ano. Assim como a campeã do Grupo Acesso, que terá o direito de desfilar no próximo ano no Grupo Especial.

O carnaval de Vitória sempre foi organizado em termos de logística pela Prefeitura de Vitória, mas esta vinha em constantes movimentos de ajustes do carnaval seja do ponto de vista financeiro, seja pela disponibilidade de tempo e planejamento para a organização do desfile, e uma das soluções foi repassar a administração do "Sambão do Povo" para a LIESES no ano de 2016. Essa contratou uma empresa privada especializada em eventos, a ECOS Eventos para organizar toda a infraestrutura antes então realizada pela prefeitura. Esta empresa gerencia hoje toda a logística para o carnaval acontecer, como venda de ingressos, sonorização, estruturas metálicas, camarotes, segurança. Quando a prefeitura repassa a administração do carnaval para a LIESES, ela recua sobre a montagem da infraestrutura física, mas mantém o apoio nas escolas de samba, impactando as comunidades com a geração de emprego e renda, valorização da identidade cultural e das manifestações populares. A economia prevista foi de $\mathrm{R} \$ 8.000 .000,00$ em quatro anos desde que o novo modelo foi pensado.

\section{Gestão colaborativa PaRa PRODUÇÃo do CARNAVAL}

Considerando a dinâmica do carnaval em Vitória, podemos perceber a participação dos três setores da economia na organização do festival: governo, empresas e organizações da sociedade civil. Para que estes atores consigam produzir o festival, torna-se necessário que um arranjo organizacional que permita a colaboração entre eles para que os objetivos da festa sejam alcançados. Neste momento, conforme argumentam Ansell \& Gash (2008), diversos mecanismos de interação e elementos contextuais são ativados, permitindo esta colaboração.

\subsection{Condições iniciais}

A origem da colaboração no carnaval capixaba nos remete a 1956 com criação da União das Batucadas e Escolas de Samba (UBES). Segundo Monteiro (2010), diante da incapacidade da UBES de gerenciar o crescente número de agremiações nos anos seguintes, em 1985 foi criada a Associação Capixaba de Escolas de Samba (ACES). Esta, posteriormente deu lugar à UESES (União das Escolas de Samba do Espírito Santo), fundada 1991, e finalmente a LICES e seus desdobramentos apresentados anteriormente.

O espírito colaborativo e a vontade dos interessados no evento também se mostraram presentes na construção do Sambão do Povo. Ao perceberem que sambódromo não seria concluído a tempo do carnaval de 1987, sambistas de várias escolas se uniram aos operários para finalização do complexo (Monteiro, 2010). 

PROD...

No entanto, com a notoriedade que as escolas estavam adquirindo com seus desfiles, cresceu o interesse de empresas capixabas associarem suas marcas às agremiações.

Apesar da história desta colaboração demonstrar um interesse da classe empresarial capixaba na participação deste evento, os entrevistados destacaram como baixa e alguns, como praticamente inexistente, a atual participação das empresas neste evento. $O$ Entrevistado 1, ao ser questionado sobre quais seriam as principais empresas que colaboram com desfile das escolas de samba do carnaval capixaba, foi enfático ao responder que "nenhuma". Ao responder a mesma pergunta, o Entrevistado 2 afirmou que com relação à iniciativa privada "[...] pra não dizer na totalidade 2 ou $3 \%$ colabora com o carnaval capixaba". Por sua vez, ao responder este mesmo questionamento, o Entrevistado 4 afirmou que naquele ano diminuiu a participação das empresas no evento, o que ele acreditava ser atribuído à crise financeira. Contudo, destaca o aspecto mercantilista do evento, ao afirmar que "[...] sempre tem alguma empresa interessada num enredo [...]" (Entrevistado 4). De maneira semelhante, o Entrevistado 5 classifica a participação das empresas como "muito baixa", "principalmente pela mídia" e atribui este fato à necessidade do carnaval “[...] se profissionalizar mais, no sentido de gestão [...]”, o que contribuiria para o aumento na captação de investimentos.

$\mathrm{Na}$ década de 1990 um aumento no número de agremiações gerou um clima de confusão na estrutura colaborativa, uma vez que a Prefeitura Municipal de Vitória, naquela época sob a administração de Vitor Buaiz, "[...] ficou temerosa de que a criação de novas escolas fosse apenas mais uma forma de captação de recursos junto à prefeitura e empresas [...]” o que levou este ente, em 1992, “[...] cortar toda a verba pública destinada às escolas e ficar apenas com a manutenção do sambódromo e a organização do desfile” (Monteiro, 2010, p. 98). Assim, como forma de protesto, as escolas decidiram não realizar desfile no ano de 1993 e captar mais dinheiro para o ano seguinte. Contudo, foram surpreendidas com a gestão do governador Paulo Hartung que "[...] retirou os desfiles carnavalescos do calendário de festas da cidade, o que extinguiu todas as agremiações ainda em atividade” (Monteiro, 2010, pp. 99-100) e o retorno desta festividade somente aconteceria quatro anos depois, em 1998.

Já o ano de 2000 foi marcado pelo início do televisionamento dos desfiles para todo o Estado, através da TV Capixaba. Está é considerada por alguns dos entrevistados um dos principais agentes na produção do evento. O Entrevistado 6 destaca que "uma grande parceira do carnaval é a TV Capixaba". Com o passar dos anos, o carnaval capixaba evoluiu e mais agremiações se juntaram, deste modo, como o número de agentes envolvidos aumentou, houve uma intensificação da estrutura colaborativa.

Analisando estes eventos a partir do modelo de Ansell e Gash (2008), percebemos que o histórico do evento, os incentivos para participação e o desequilíbrio de recursos financeiros influenciaram no resultado da experiência colaborativa. Observa-se assim, que desde o seu nascimento, desfile das escolas de samba do carnaval capixaba trabalha em colaboração entre Escolas de Samba, poder público e empresas. A produção desta festividade, uma vez que se caracteriza como uma rede colaborativa, compartilha conhecimento e interações sociais relevantes para o resultado deste evento. Por isso a participação de agentes empresariais e da prefeitura, assume particular relevância no resultado e na qualidade do evento.

\subsection{Desenho Institucional}

Inicialmente, compete salientar que a organização do desfile das escolas de samba do carnaval capixaba competia à Prefeitura Municipal de Vitória (PMV) até 2015, tendo sofrido mudança da gestão, principalmente, em virtude da crise financeira do final daquele ano. Os relatos dos Entrevistados 5 e 12 mostram que naquele mesmo ano já se observava o início da articulação para realização desta transição de gestão. Na ocasião, estudava-se repartir os custos do evento entre a Prefeitura de Vitória, de Cariacica, de Vila Velha, da Serra e o Governo do Estado. Contudo, esta ideia não vigorou e uma nova configuração foi formada, na qual a LIESGE e LIESES assumiram a gestão do evento, com o apoio da Prefeitura Municipal de Vitória. 
Em virtude do pouco prazo para a produção do evento e da ausência de competência técnica, a LIESGE e LIESES contrataram uma empresa especializada em eventos para produção do desfile das escolas de samba. Conforme relata o Entrevistado 1 ao afirmar que antes desse período era da PMV a responsabilidade pela montagem do "palco do espetáculo". Contudo, quando esta responsabilidade foi transferida para as Ligas, estas optaram por contratar uma empresa especializada ao perceber que não possuíam competências técnicas para realizar o evento naquele momento. Esta decisão aconteceu em outubro de 2015, deixando a Liga com um prazo de apenas três meses para organizar a festividade, que estava agendada para o final de janeiro de 2016. Observa-se assim que este último ano foi tumultuado, marcado pela alteração das regras que conduziam a realização deste evento. Esta mudança no desenho institucional também é mencionada pelo Entrevistado 9, que afirma que além da crise financeira, esta mudança foi “[...] uma oportunidade de tentar mexer nesse modelo de gestão de dinheiro público, numa festa que não é para todos [...]”.

Em virtude da crise financeira e da remodelagem do perfil da gestão dos recursos públicos, as Escolas de Samba tiveram que intensificar o seu processo de prestação de contas e transparência. Sobre este ponto, o Entrevistado 2 afirma que “[...] o dinheiro só é cedido no próximo ano quando você presta conta do ano anterior, então ajustes fiscais tem que ser feito [...]”. E acrescenta que:

[...] Nós estamos num Brasil novo [...], você vê muitas mudanças e uma das mudanças que tá acarretando muito problema é a Lei de Responsabilidade Fiscal. Então a lei de responsabilidade fiscal coloca o gestor numa calça justa, que ele não tem mais como, hoje, fazer gastos desnecessários (Entrevistado 2).

Seguindo o Entrevistado 9, o Entrevistado 11 salienta as dificuldades em se empregar dinheiro público em uma festa que não é destinada à totalidade da população.

\begin{abstract}
E também as bancadas políticas hoje, a maior parte delas são evangélicas também, então se bate muito em gastar o dinheiro público, tem que ser gasto para uma totalidade e o carnaval não é uma totalidade. Existe um grupo que gosta e tem outro que não gosta, então tomando por isso o gasto da Prefeitura de Vitória era em torno 7 a 8 milhões por cada carnaval. Mas, esse 7 a 8 milhóes, com as escolas de samba só era gasto 3 . Mas, caía tudo em cima do carnaval capixaba, quando fala carnaval capixaba é carnaval das escolas de samba (Entrevistado 11).
\end{abstract}

Os Entrevistados mostram que estas dificuldades na captação de recursos, tanto por parte da iniciativa privada quanto da esfera pública, intensifica a necessidade de que este modelo colaborativo adote um novo desenho institucional, com proposta de inclusão participativa, por meio de fórum e assembleias, com regras claras e transparência do processo.

\title{
6.3 Liderança facilitadora
}

Conforme anteriormente mencionado, as ligas (LIESGE e LIESES) assumiram no final de 2015 a gestão do carnaval. Deste modo, passaram a configurar no polo central desta rede colaborativa, assumindo a função de liderança facilitadora. Isto posto, as ligas buscaram disciplinar o carnaval capixaba por meio de dois regulamentos, um destinado ao Grupo Especial e outro ao Grupo A (grupo de acesso). A versão de 2016 destes documentos destacou as competências de cada entidade na produção do evento.

Ambos os regulamentos elencam que compete à PMV a responsabilidade pela "adoção das medidas logísticas relativas aos desfiles, nos termos do disposto no contrato" celebrado com a LIESGE e LIESES. Com isso, buscou-se delimitar de maneira formal a competência de cada entidade na produção do desfile das escolas de samba do carnaval capixaba, destinando à PMV a logística do evento e para as Ligas a direção artística. Acrescentado a isso, o Entrevistado 13 relatou que em relação ao desfile, "a Liga é responsável por montar o calendário [...] com o período de escolha de enredo, samba enredo, gravação, lançamento do CD, ensaios técnicos". Bem como, "[...] aprova regulamento dos grupos que estão em jogo para o desfile".

Apesar do prescrito nos regulamentos, o Entrevistado 11 e 16 acrescentou que a "logística do Sambão do Povo", na regra é uma responsabilidade da PMV, mas na prática acabou sendo transferida para as Ligas. Esta 
incompatibilidade entre os regulamentos e os dados apresentados nas entrevistas pode estar relacionada ao período no qual os regulamentos foram elaborados. Como a mudança da gestão ocorreu apenas no final de 2015 e o desfile das escolas de samba foram realizados em janeiro de 2016, fica claro que os regulamentos se referem ao cenário anterior e criam uma nova configuração de liderança do evento.

Deste modo, diversos entrevistados destacam o papel articulador do atual presidente da LIESGE, atribuindo a ele os méritos pela comunicação com os agentes governamentais e com as empresas. De acordo com o Entrevistado 4, a Liga "[...] é uma gestora do carnaval, ela administra os recursos e a festa, propriamente dita [...]”, por meio de financiamento do Estado do Espírito Santo e da PMV. Sendo que, parte do recurso destinado a custear as despesas da LIESGE e LIESES e outra parte repassada às Escolas de Samba. Conforme este entrevistado, a Liga “[...] distribui em partes previamente acordadas entre as escolas, as escolas do grupo especial recebem uma verba um pouco maior, as escolas do grupo A recebem menos".

Com relação ao carnaval de 2016, o Entrevistado 3 destaca que apesar do pouco tempo destinado à produção do evento “[...] todo mundo acreditou muito. E todo mundo viu que se não se unissem, não dessem as mãos, o carnaval não iria acontecer”. Em termos operacionais, diversos entrevistados ressaltam que as decisões sempre ocorrem por meio de votações em reuniões e assembleias, sendo que nada é imposto pela direção das Ligas, que compreendem a diversidade de interesses envolvidos neste processo. Assim, observase que as decisões são tomadas obedecendo a lógica bottom-up (de baixo para cima) proposta por Fung e Wright (2003) aos modelos participativos de gestão. Isto posto, observa-se algumas características marcantes da atuação da LIESGE e LIESES como agente fundamental para o desenvolvimento do processo colaborativo da produção do carnaval capixaba.

\subsection{Processo colaborativo}

Por fim, convém analisar como se estrutura o processo colaborativo da produção do carnaval capixaba. Conforme já demonstrado, o processo colaborativo envolve diálogo face-a-face, construção da confiança, compromisso com o processo, entendimento compartilhado e resultados intermediários (Ansell \& Gash, 2008). Com relação ao diálogo face-a-face, tem-se que as decisões para a produção ocorrem por meio de fóruns coletivos, nos quais são negociados os interesses das Escolas de Samba. Sobre este assunto, o Entrevistado 1 afirma que, “[...] quando a Liga faz uma reunião, é reunião de regulamento, é reunião para falar de comissão julgadora, é reunião pra falar de captação de recursos, então são assuntos de total interesse delas".

A busca pela construção de um ambiente de diálogo na gestão colaborativa se mostra essencial para identificar oportunidades de ganho mútuo. No entanto, na gestão colaborativa, este diálogo é mais do que uma simples negociação, uma vez que existe a necessidade de se quebrar estereótipos e outras barreiras do processo de comunicação. Esta necessidade se torna ainda mais evidente quando trazida ao contexto do carnaval, cuja essência já é marcada pela diversidade cultural. Neste contexto, a compreensão da necessidade de ganhos mútuos aparenta ser uma realidade quando se analisa a postura da Prefeitura Municipal de Vitória. De acordo com o Entrevistado 2, a prefeitura percebeu a importância deste evento para a geração de empregos, contudo, ressalta que esta percepção ainda é muito limitada. Conforme o Entrevistado 3 afirma, "o poder público, talvez, não dê a devida importância ainda a esse evento, mas é um evento que vem crescendo ano a ano $[\ldots] "$.

Uma ressalva é feita pelo Entrevistado 1 quando afirma que “[...] o Governo, a Prefeitura, entendem que vale a pena investir porque sabem que o carnaval retorna para a comunidade, em torno das escolas, em forma de emprego, tirando pessoas da ociosidade. Muitos hoje vivem do carnaval". Neste sentido, o Entrevistado 15 salienta que se a LIESGE e LIESES não fossem entidades sérias, a PMV não teria delegado a responsabilidade pela gestão do carnaval. E salienta ainda que “[...] foi muito correta, a prestação de conta ano a ano, a LIESES presta conta há não sei quantos anos [...]”. 
Com relação ao compromisso com o processo colaborativo, observa-se o reconhecimento da interdependência dos agentes envolvidos, principalmente por parte das Ligas. De acordo com o Entrevistado 14, “[...] o que ela pode facilitar pra escola, ela faz isso, então, por exemplo, ela fez, eu acho que, salvo engano, a tinta ela fez uma troca de merchandising, e ai o fornecedor ofereceu tinta e ela dividiu entre as escolas [...]". Ainda em relação ao compromisso, o Entrevistado 3 destaca que, ao tratar do pouco tempo destinado à produção do evento, “[...] todo mundo acreditou muito. E todo mundo viu que se não se unissem, não dessem as mãos, o carnaval não iria acontecer”. Assim, conforme proposto por Ansell e Gash (2008) o compromisso com o processo colaborativo torna-se uma variável determinante para o sucesso ou fracasso da experiência colaborativa e irá sustentar a busca por um entendimento coletivo.

Por fim, a busca por resultados intermediários é demonstrada na fala do Entrevistado 4, que afirma que uma parcela dos recursos repassados pelos agentes públicos à Liga é distribuída entre as escolas do Grupo Especial e do Grupo A, e acrescenta ainda que "O relacionamento entre as escolas de samba, é um relacionamento muito bom, tanto que são chamadas de co-irmãs, né. Mas eu digo que esse relacionamento de co-irmã é mais porque tá todo mundo no mesmo barco, afundando. Do que num barco navegando”.

Esta fala, confirma uma premissa básica de Ansell e Gash (2008) que a colaboração costuma acontecer de forma mais eficaz em ambientes nos quais as vantagens são distribuídas de maneira igualitária entre os atores envolvidos na colaboração.

\section{CONSIDERAÇÕES FINAIS}

Com base no exposto observa-se que o modelo de gestão colaborativa ajuda a compreender os principais aspectos da produção do carnaval capixaba uma vez que permite responder as instabilidades típicas deste setor e envolver os agentes em prol de um entendimento mútuo e de uma estrutura de ganha-ganha.

As condições iniciais do processo colaborativo denotam um ambiente conturbado de articulação com a esfera pública e privada. Observou-se que por diversas vezes as Escolas de Samba tiveram problemas na negociação com estes atores. Contudo, este cenário nunca prejudicou o clima de confiança com relação à produção do evento. Fato este, inclusive, presenciado na produção do carnaval de 2016, quando houve uma alteração no desenho institucional em virtude da crise financeira. Apesar do pouco tempo destinado à produção do mesmo, constatou-se que o relacionamento entre os atores não foi abalado.

Alinhado a isto, tem-se a presença da LIESGE e LIESES que representam uma liderança facilitadora perante as agremiações a estas filiadas. Ao aproximar as próprias escolas, com as empresas e com os Governos Municipais e Estadual em prol da produção carnaval capixaba, tem se mostrado indispensável para a manutenção da estrutura colaborativa. Embora a prefeitura aparente deter alguma autoridade, em virtude do seu poder político e econômico, isto não descaracteriza a atuação das Ligas como facilitadoras do processo. Nesta liderança reside um dos fatores fundamentais para o sucesso do evento, o perfil facilitador, uma vez que gerenciam a dinâmica das relações entre agentes públicos, privados e sociedade civil.

Observa-se que apesar do pouco tempo desta entidade como principal responsável pela gestão do evento, esta já vinha assumindo uma postura facilitadora ao se posicionar ativamente no processo de captação de recursos e articulação dos interesses das Escolas de Samba perante o poder público e a iniciativa privada. Além disso, foi possível verificar que as decisões neste ambiente obedecem a uma lógica do tipo bottom-up (de baixo para cima), fomentada pela postura inclusiva e facilitadora da LIESGE e LIESES. Estas duas organizações mostraram-se fundamentais para que o processo colaborativo fosse operacionalizado e promovesse o sucesso do evento. 


\section{REFERÊNCIAS}

Alonso, A. D., \& Bressan, A. (2013). Stakeholders' Perspectives on the Evolution and Benefits of a Traditional Wine Festival. Journal of Convention \& Event Tourism, 14(4), 309-330.

Andersson, Tommy. D; Getz, Donald (2009). Tourism as a mixed industry: differences between private, public and not-for-profit festivals. Tourism Management, v. 30, n.6, p. 847-856, 2009.

Ansell, C., \& Gash, A. (2008). Collaborative governance in theory and practice. Journal of Public Administration Research and Theory, 18(4), 543-571.

Bardin, L. (2004). Análise de conteúdo. Lisboa: Edições 70.

Blass, L. M. (2008). Rompendo fronteiras: a cidade do samba no Rio de Janeiro. Revista Brasileira de Ciências Sociais, 23(66), 79-92.

Cabral, S., Krane, D., \& Dantas, F. (2013). A dança dos blocos, empresários, políticos e técnicos: condicionantes da dinâmica de colaboração interorganizacional do carnaval de Salvador. Organizaçôes \& Sociedade, 20(64), $145-163$.

Cabral, S., \& Krane, D. (2018). Civic festivals and collaborative governance. International Review of Administrative Sciences, 84(1), 185-205.

Chrislip, D. (2002). The collaborative leadership fieldbook: a guide for citizens and civic leaders. San Francisco: JosseyBass.

Comunian, R. (2011). Rethinking the creative city: the role of complexity, networks and interactions in the urban creative economy. Urban Studies, 8(6), 1157-1179.

Damatta, R. (1979). Carnavais, malandros e heróis: para uma sociologia do dilema brasileiro. Rio de Janeiro: Rocco.

Denzin, N., \& Lincoln, Y. (2000). Introduction: the discipline and practice of qualitative research. In N. Denzin, \& Y. Lincoln (Eds.). Handbook of Qualitative Research. 2.ed. Thousand Oaks: Sage.

Emery, Y., \& Giauque, D. (2014). The hybrid universe of public administration in the 21st century. International Review of Administrative Sciences, 80(1), 23-32.

Farazmand, A. (2012). The future of public administration: Challenges and opportunities: a critical perspective. Administration \& Society, 44(4), 487-517.

Fung, A., \& Wright, E. (2003). Deepening democracy: innovations in empowered participatory governance. Politics \& Society, 29(1), 5-41.

Getz, D. (2002). Why festivals fail. Event Management, 7(4), 209-219.

Getz, D. (2010). The nature and scope of festival studies. International Journal of Event Management Research, 5(1), $1-47$.

Getz, D., \& Andersson, T. (2010). Festival stakeholders: exploring relationships and dependency through a fourcountry comparison. Journal of Hospitality \& Tourism Research, 34(4), 531-556.

Getz, D., \& Page, S. (2016). Progress and prospects for event tourism research. Tourism Management, 52(1), 593-631.

Jeffcutt, P. (2000). Management and the creative industries. Studies in Culture, Organizations and Society, 6(2), 123-127.

Monteiro, L. (2010). Carnaval capixaba: histórias, honras e glórias. Serra, ES: Editora do Autor.

Noy, C. (2008). Sampling knowledge: The hermeneutics of snowball sampling in qualitative research. International Journal of social research methodology, 11(4), 327-344.

Prestes Filho, L. C. (2009). Cadeia produtiva da economia do carnaval. Rio de Janeiro: Editora E-papers.

Risério, A. (1995). Carnaval: as cores da mudança. Afro-A\#sia, 16(1), 90-106.

Sandfort, J., \& Milward, B. (2008). Collaborative service provision in the public service. In S. Cropper (Ed.). The Oxford Handbook of Inter-Organizational Relations. Oxford: Oxford University Press.

Santos, F. B. (2010). Carnaval e administração pública: o papel dos governos locais na configuração das festas. Cultura e Arte Popular, 7(2), 61-74. 
Scott, A. (2008). Social Economy of the Metropolis: cognitive-cultural capitalism and the global resurgence of cities. Oxford: Oxford University Press.

Throsby, D. (1995). Culture, economics and sustainability. Journal of Cultural Economics, 19(3), 199-206.

Tureta, C., \& Araújo, B. F. V. B. (2013). Escolas de Samba: trajetórias, contradições e contribuições para os estudos organizacionais. Organizações \& Sociedade, 20(64), 111-129.

\section{Notas}

[1] Agradecemos a Fundação de Amparo à Pesquisa e Inovação do Espírito Santo (FAPES) pelo financiamento desta pesquisa. 